\title{
Diagnostic dilemmas of an eccentrically located gestation sac: role of 3D ultrasound
}

\author{
Selvaraj Ravi Lakshmy*, Thasleem Ziyaulla, Shobana Umapathy
}

Department of Fetal Medicine, Shri Lakshmi Clinic and Scan Centre, Krishnagiri, Tamil Nadu, India

Received: 05 October 2019

Revised: 11 November 2019

Accepted: 16 November 2019

\section{*Correspondence:}

Dr. Lakshmy Ravi Selvaraj,

E-mail: drlakshmiravi@gmail.com

Copyright: (c) the author(s), publisher and licensee Medip Academy. This is an open-access article distributed under the terms of the Creative Commons Attribution Non-Commercial License, which permits unrestricted non-commercial use, distribution, and reproduction in any medium, provided the original work is properly cited.

\begin{abstract}
Background: Differential diagnosis of an eccentrically located sac includes interstitial pregnancy, true cornual pregnancy and angular pregnancy which may all look similar on 2D (two dimensional) ultrasound. Interstitial pregnancy is associated with a higher maternal mortality and needs to be differentiated from true cornual pregnancy and angular pregnancy. This paper is an illustration of the role of 3D (three dimensional) ultrasound in differential diagnosis and management of the three entities.

Methods: 2D and 3D ultrasound findings were analyzed in 10 cases of eccentrically located sac. The role of 3D ultrasound in differentiating the three entities had been evaluated.

Results: The presence of an eccentrically located gestation sac with incomplete or asymmetric myometrial tissue less than $5 \mathrm{~mm}$ in thickness on 2D and the coronal sections obtained from 3D scans were used for diagnosis of interstitial pregnancy in three cases. 2 cases of angular pregnancy were diagnosed based on the finding of sac located in one of the lateral angles of the uterus with broad based connection to the endometrium. 2 cases of cornual pregnancy one intrauterine in a bicornuate uterus and the other in a rudimentary horn has been described. One heterotopic pregnancy and two other cases where a cornual fibroid mimics interstitial pregnancy is also illustrated.

Conclusions: The role of 3D ultrasound in differentiating the three entities and the key findings in obtaining the precise diagnosis are emphasized. Routine usage of 3D ultrasound in all cases of eccentrically located gestational sac is recommended.
\end{abstract}

Keywords: Angular pregnancy, Cornual pregnancy, Interstitial pregnancy, 3D ultrasound

\section{INTRODUCTION}

Early pregnancy scan is aimed at locating the sac and to check for fetal viability. The differential diagnosis of an eccentric located gestation sac includes interstitial, cornual and angular pregnancy. Interstitial pregnancy poses a significant diagnostic and therapeutic challenge and is associated with significantly higher maternal mortality rate. One in every 2500-5000 live births and approximately 2 to $4 \%$ of all ectopic gestations account for interstitial ectopic pregnancy. ${ }^{1-5}$ The incidence of interstitial ectopic pregnancy may have been falsely interpreted in literature due to interchanging the terminologies for interstitial, cornual and angular pregnancy. With the increase in tubal surgeries, genital infections and treatment for infertility the incidence of ectopic pregnancy is also increasing steadily. ${ }^{6,7}$ Delay in diagnosis contributes to high mortality rate $(2.5 \%)$ compared to other forms of tubal ectopic $(0.14 \%){ }^{2}$ Understanding that interstitial pregnancy, true cornual pregnancy and angular pregnancy are separate entities and that the natural course and outcome of each condition 
is different makes it essential to arrive at correct diagnosis for prompt treatment and to avoid a catastrophe. 3D ultrasound is very useful in obtaining the coronal scans of the fundal region of the uterus along with superior and lateral myometrial stripes giving a better overview of the cornual regions of the uterus which cannot be done with routine 2D ultrasound. ${ }^{8}$

\section{METHODS}

Pregnant women who enrolled for early pregnancy scans to our centre in whom eccentric location of gestational sac was identified on routine 2D ultrasound were included in the study. This included case diagnosed at a routine early pregnancy scan and also those cases which were referred to us for an expert opinion. About 10 cases which fulfilled this criterion during our study period from January 2017 to December 2018 were subjected to transabdominal and transvaginal examination of pelvis after obtaining informed consent from them. Cases in whom a definitive diagnosis of a normal intrauterine location of gestation sac was established, and other forms of ectopic pregnancy were excluded from this study. Examinations were performed using GE Voluson 730 Pro, Voluson E8 and Voluson E10. (GE Healthcare, Kretztechnik, Zipf, Austria). Transvaginal 3D scans were obtained in all cases and volume data sets were acquired. Under adequate magnification the volume was obtained in the sagittal section from one side of the uterus to the other. Care was taken to include the eccentrically located gestation sac during volume acquisition. Volume acquisition was also done in the transverse section of uterus if the sac could not be included in sagittal sections. The volume data sets were manipulated to obtain the coronal section of uterus, this could be done either by rendering the uterus or using the $\mathrm{Z}$ plane in multiplanar imaging. Addition of VCI (volume contrast imaging) further improved endomyometrial delineation and location of eccentric located gestation sac. Rendering of the uterus was done in surface mode and HD live mode. $3 \mathrm{D}$ volume data acquisition and postprocessing of the acquired data set was the preferred technique rather than 4D acquisition. Follow up was obtained in all cases.

\section{RESULTS}

The results of the cases which presented to us with an eccentrically located gestation sac at early pregnancy scan are as follows. In the 10 cases about $30 \%(n=3)$ were interstitial pregnancy, $20 \%(\mathrm{n}=2)$ had cornual pregnancy, $20 \%(\mathrm{n}=2)$ had angular pregnancy, $20 \%(\mathrm{n}=$ 2) were cases of cornual fibroid mimicking an interstitial pregnancy and $10 \%$ was a case of heterotopic pregnancy.

Case 1 is an example of an interstitial pregnancy diagnosed at routine early pregnancy scan. Fig $1 \mathrm{a}$ and $1 \mathrm{~b}$ are transabdominal images which depicts the eccentrically placed gestation sac in sagittal and transverse sections respectively. Figure 1c and 1d are transvaginal images which shows the sac located away from the endometrium and a viable pregnancy of 7 weeks. Three-dimensional image (Figure 1e) illustrates the gestation sac separated from the endometrium by an intervening myometrial band and Figure if shows the lack of sufficient myometrium surrounding the sac.
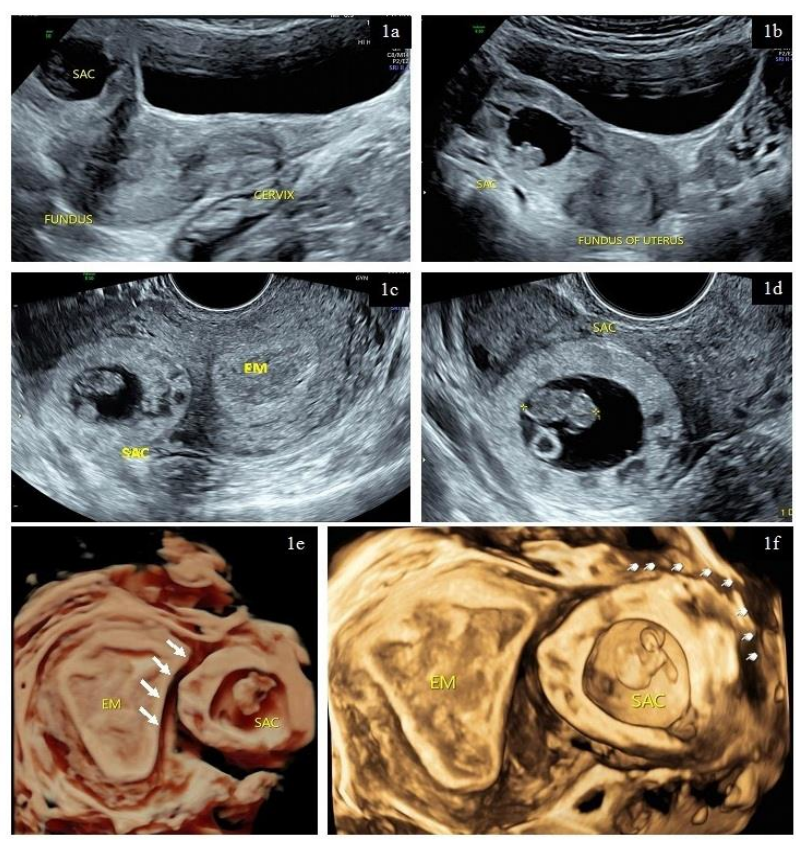

Figure 1: Interstitial pregnancy - Case 1.

(1a) Transabdominal sagittal section of uterus depicting laterally placed sac, (1b) Transverse section at fundus of uterus illustrating eccentric sac, (1c) trans-vaginal image of sac seen separate from endometrial cavity, (1d) CRL measures $11 \mathrm{~mm}$ with cardiac activity, (1e) 3D image illustrating sac separate from endometrial cavity by an intervening myometrial band (arrows), (1f) 3D image showing thin myometrial mantle (arrows).

Case 2 had been referred to us with non-visualisation of gestation sac and raised b-hcg levels. Transabdominal (Figure 2a) and transvaginal (Figure 2b) image shows bulky uterus with features suggestive of adenomyosis with no evidence of gestation sac. Transabdominal imaging with a high frequency probe revealed a viable interstitial pregnancy (Figure 2c) with perigestational vascularity (Figure 2d). 3D images illustrate the exact location of sac with insufficient myometrial mantle (Figure 2e and 2f).

Case 3 had been referred to us as tubal ectopic gestation. Figure 3a shows transabdominal sagittal section of uterus with non-visualization of sac. Figure $3 b$ is a transverse section of uterine fundus depicting the tubal echogenic ring with sac placed at the lateral end of the uterine fundus. Transvaginal image depicts empty endometrial cavity with a small echogenic lesion (arrow) at the lateral end of endometrial cavity (Figure 3c) and tubal ring sign in adnexa (Figure 3d). Three-dimensional image clearly illustrates the sac located in the intramural portion of the 
tube with a small intrauterine extension into the endometrial cavity (Figure $3 \mathrm{e}$ and $3 \mathrm{f}$ ).

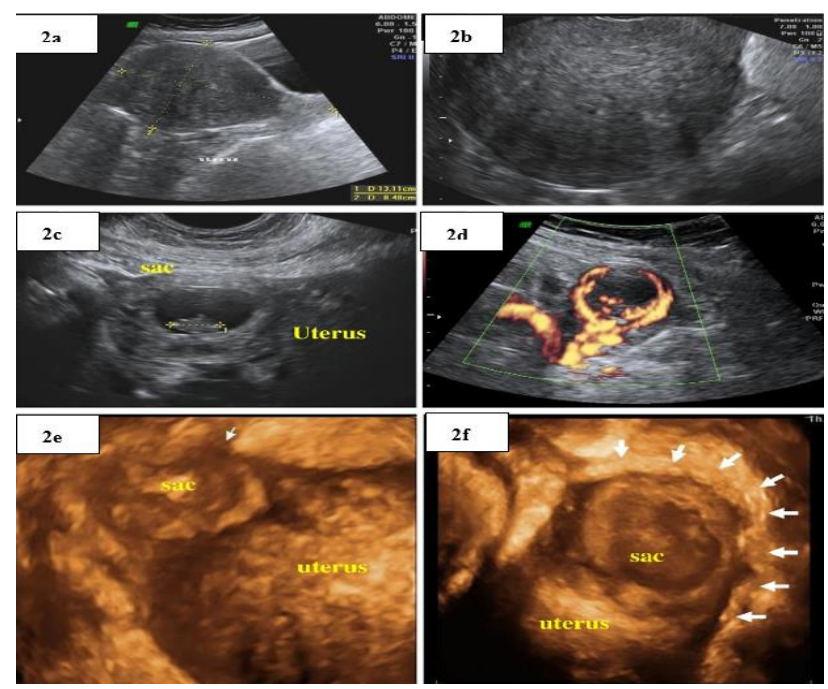

Figure 2: Interstitial Pregnancy - Case 2.

(2a and $2 b)$ Transabdominal and transvaginal images shows bulky uterus with features suggestive of adenomyosis and nonvisualization of gestation sac, (2c) Eccentrically located gestation sac in the cornual end of uterus, (2d) Peripheral vascularity of sac, (2e)

3D image showing sac implanted in the cornua of uterus, (2f) Arrows show thin myometrial mantle in the lateral aspect of gestational sac.
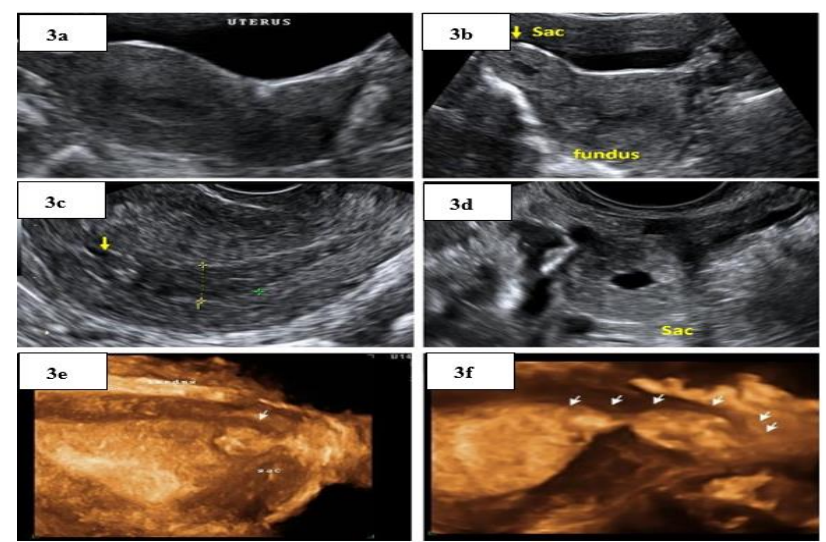

Figure 3: Interstitial Pregnancy with small Intra Uterine Extension - Case 3.

(3a) Transabdominal sagittal section of uterus with nonvisualiation of sac, (3b) Transverse section of uterine fundus depicting the tubal gestation ring at the lateral end of uterus, (3c) Transvaginal image depicts empty endometrial cavity with a small echogenic lesion (arrow) at the lateral end of endometrial cavity, (3d) Transvaginal image showing the tubal ring sign in adnexa, (3e) 3D imaging -

Interstitial ectopic gestation with small intrauterine extension (arrow), (3f) 3D imaging - Interstitial ectopic gestation with small intrauterine extension. Arrows pointed along the entire course of eccentric sac.
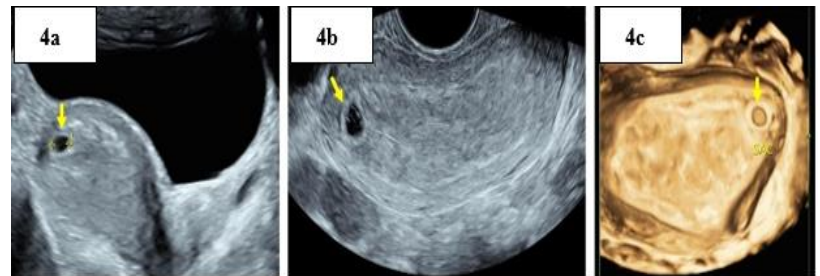

Figure 4: Angular pregnancy - Case 1.

(4a and 4b) Transabdominal and transvaginal image of eccentrically located sac (arrow) in angular pregnancy, (4c) 3D image showing gestational sac (arrow) in the superolateral angle of the uterus.
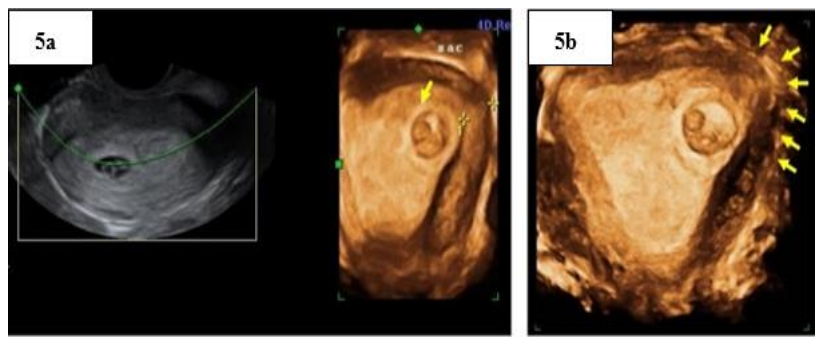

Figure 5: Angular pregnancy - Case 2.

(5a) Eccentric gestation sac (arrow) located in the lateral angle of endometrial cavity, note the large

broad-based connection with endometrium, (5b)

Arrows point to the normal myometrium noted on the lateral angle.
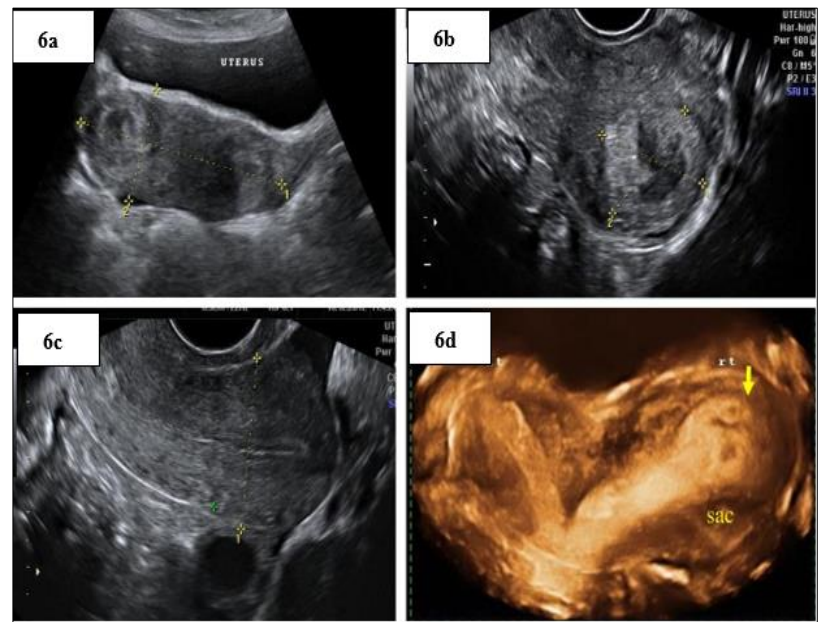

Figure 6: Cornual pregnancy in bicornuate uterus. (6a and 6b) Transabdominal image and transvaginal image of eccentrically located gestational sac, (6c)

Empty uterine cavity, (6d) 3D ultrasound depicting a bicornuate uterus with gestational sac noted in one cornua (arrow).

Case 4 and 5 are two cases with an eccentrically located gestation sac where 3D ultrasound clearly depicts the lateral implantation of the sac in the endometrial cavity proving it as an angular pregnancy. Figure $4 \mathrm{a}$ and $4 \mathrm{~b}$ shows the transabdominal and transvaginal images of eccentrically located sac in angular pregnancy on $2 \mathrm{D}$ 
ultrasound. Figure $4 \mathrm{c}$ is a $3 \mathrm{D}$ illustration of gestational sac in the superolateral angle of the uterus. Fig 5a depicts another case of angular pregnancy, note that the gestation sac is completely surrounded by endometrium and there is sufficient myometrium on the lateral angle of uterus in Figure 5b.

Case 6 is an example of true cornual pregnancy in one horn of bicornuate uterus. Figure $6 \mathrm{a}$ and $6 \mathrm{~b}$ are transabdominal and transvaginal images of eccentrically placed gestation sac. Figure 6c illustrates empty uterine cavity. 3D image (Figure 6d) not only depicts the uterine anomaly but also confirms the intrauterine gestation sac located in bicornuate uterus.
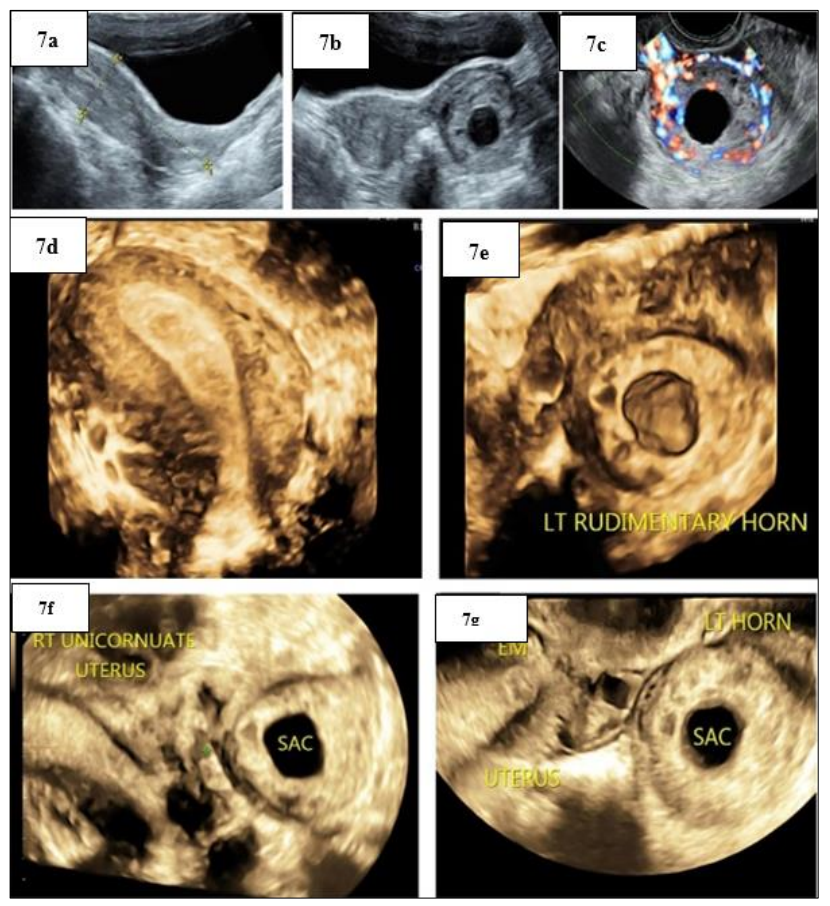

Figure 7: Cornual pregnancy in rudimentary horn.

(7a) Transabdominal image of sagittal section of uterus, (7b) Gestational sac seen separate from the uterus surrounded by myometrium, (7c) A vascular pedicle joining the gestational sac to the unicornuate uterus, (7d) 3D rendering of uterus demonstrating

right unicornuate uterus, (7e) 3D rendering of gestational sac in left rudimentary horn, (7f and 7g)

3D multiplanar imaging with VCI demonstrating unicornuate uterus with sac in left rudimentary horn.

Case 7 is an illustration of unicornuate uterus with pregnancy in rudimentary horn. Figure $7 \mathrm{a}$ shows the transabdominal image of sagittal section of uterus. In Figure $7 \mathrm{~b}$ gestational sac is seen separate from the uterus surrounded by myometrium and Figure $7 \mathrm{c}$ shows a vascular pedicle joining the gestational sac to the unicornuate uterus. Rendered 3D image depicts the right unicornuate uterus (Figure 7d) and gestational sac in left rudimentary horn (Figure 7e). 3D multiplanar imaging with VCI demonstrating unicornuate uterus with sac in left rudimentary horn (Figure $7 \mathrm{f}$ and $7 \mathrm{~g}$ ).
Case 8 is an example of how a cornual fibroid can mimic an interstitial pregnancy. Figure $8 \mathrm{a}$ and Figure $8 \mathrm{~b}$ are transabdominal images showing sagittal and transverse section of the fundus of the uterus illustrating eccentric hypoechoic lesion. Figure 8c shows hypoechoic areas of degeneration in a cornual fibroid on TVS and note the perilesional vascularity mimicking an interstial pregnancy (Figure 8d). Figure 8e and 8f are 3D images showing cornual fibroid with sufficient myometrium around the lesion. Review scan after two weeks demonstrated the same ultrasound findings (Figure $8 \mathrm{~g}$ and $8 \mathrm{~h}$ ). Non pregnant b-hcg levels aided in confirming the diagnosis of cornual fibroid.
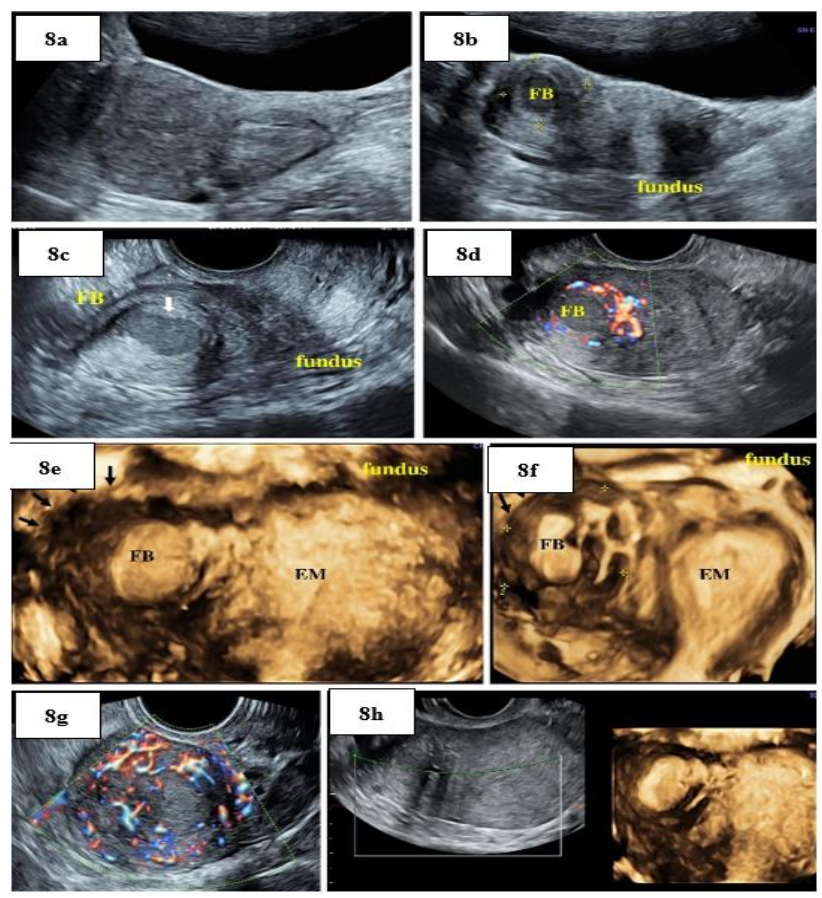

Figure 8: Cornual fibriod mimicking interstitial pregnancy. (8a) Transabdominal sagittal image of uterus, (8b) Transverse section at fundus of uterus illustrating eccentric hypoechoic lesion, (8c) Transvaginal image of cornual fibroid showing hypoechoic areas of degeneration (arrow), (8d)

Perilesional vascularity mimicking interstial pregnancy, (8e and 8f ) 3D Transvaginal image showing cornual fibroid note sufficient myometrium around the lesion (arrow), (8g and $8 \mathrm{~h}$ ) Review scan

after two weeks demonstrates same findings.

A normal intrauterine pregnancy can present with a cornual fibroid as illustrated in Case 9 Figure $9 \mathrm{a}$ is a transabdominal image of a cornual fibroid mimicking an eccentrically located sac. Figure $9 \mathrm{~b}$ illustrates the presence of intrauterine pregnancy along with the cornual fibroid. Figure $9 \mathrm{c}$ is a transvaginal image of cornual fibroid showing hypoechoic areas of degeneration in cornual fibroid and Figure $9 \mathrm{~d}$ is a 3D image depicting the endometrium and cornual fibroid. 

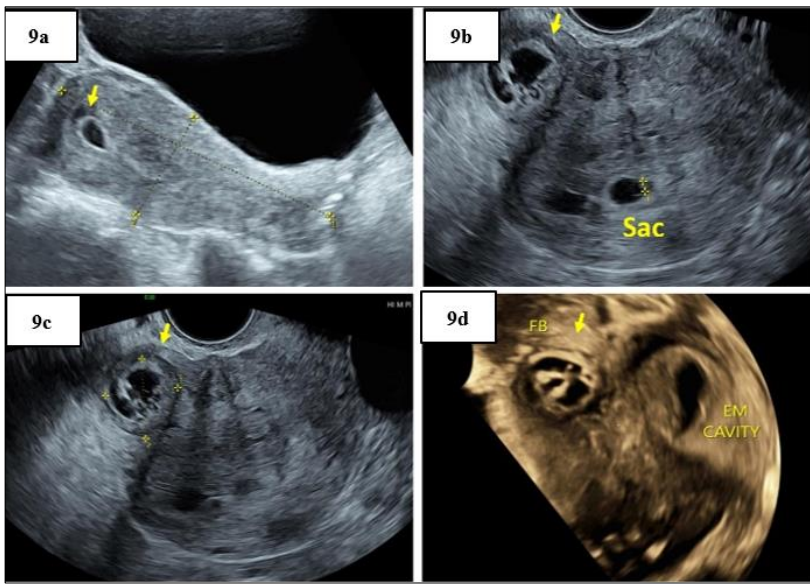

Figure 9: Cornual fibroid with coexistent intrauterine pregnancy. (9a) Transabdominal image of a cornual fibroid mimicking an eccentrically located

sac. (9b) Transvaginal image demonstrating intrauterine pregnancy (arrow points to cornual fibroid), (9c) Transvaginal image of cornual fibroid (arrow), (9d) 3D image depicting endometrium and cornual fibroid (arrow points to cornual fibroid).
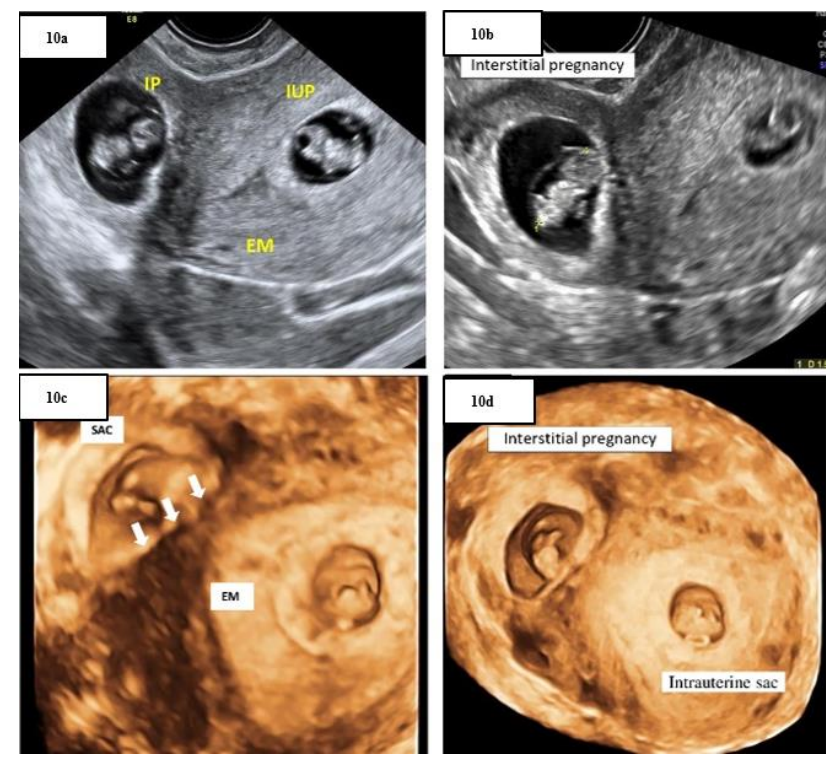

Figure 10: Heterotopic pregnancy.

(10a) Transvaginal image of an eccentrically located gestational sac along with intrauterine pregnancy. (10b) Viable interstitial pregnancy with cardiac activity, (10c and 10d) 3D image illustrating the eccentric sac separate from the endometrial cavity (arrow points to intervening myometrium).

Non-visualisation of the fetal pole or the yolk sac in the eccentrically located lesion is an additional clue to suspect the possibility of cornual fibroid. A suspicion of this possibility with expectant management and serial ultrasound follow-up would help in diagnosis of this entity. A review of the previous ultrasound reports is very useful as in this case the fibroid was already documented in the baseline pelvic scan.
Case 10 is an example of heterotopic pregnancy where one is an intrauterine pregnancy and the other is an interstitial pregnancy. Figure $10 \mathrm{a}$ is a transvaginal image of an eccentrically located gestational sac along with intrauterine pregnancy. Figure $10 \mathrm{~b}$ shows a viable interstitial pregnancy with cardiac activity. 3D images illustrate the eccentric sac separate from the endometrial cavity (Figure 10c and 10d).

\section{DISCUSSION}

\section{Interstitial pregnancy}

Implantation of the embryo in the intramural portion of the fallopian tube is called the interstitial pregnancy. ${ }^{9}$ The interstitial portion of the fallopian tube is about $1 \mathrm{~cm}$ long and $0.7 \mathrm{~cm}$ wide and is surrounded by the myometrium which has abundant blood supply from the uterine and ovarian vessels. Interstitial pregnancies tend to present relatively late at 7-12 weeks of gestation due to myometrial distensibility and due to lack of specific signs and symptoms. Rupture can lead to massive haemorrhage leading to hypovolemic shock and often death. ${ }^{10}$

Timor-Tritsch et al proposed the following diagnostic criteria based on 2D sonography which included (a) Empty uterine cavity (b) Chorionic sac separate and at least $1 \mathrm{~cm}$ from the most lateral edge of the uterine cavity and (c) A thin (less than $5 \mathrm{~mm}$ ) myometrial layer surrounding the gestational sac. ${ }^{11}$ The popularly known "interstitial line sign" was proposed by Ackerman et al. ${ }^{12}$ The interstitial line sign is an echogenic line extending from the endometrial cavity to the cornua of the uterus abutting the midportion of the gestational sac and it had better sensitivity (80\%) and specificity (98\%) than eccentric gestational sac location (sensitivity, 40\%; specificity, $88 \%$ ) and myometrial thinning (sensitivity, $40 \%$; specificity, 93\%) for the diagnosis of interstitial pregnancy. Application of the $1 \mathrm{~cm}$ cut-off proposed by Tritsch et al was questioned and later a combination of the two findings for the diagnosis of interstitial pregnancy had been proposed: visualization of the interstitial line and the continuation of myometrial mantle around the ectopic sac. ${ }^{13,14}$

However these criteria are reproducible only in first trimester and the diagnosis become more difficult and equivocal when the gestation sac enlarges in the second trimester. ${ }^{1,12,15}$ It is difficult to assess an eccentrically located gestation sac during routine 2D ultrasound. ${ }^{16,17}$ Many case series have been reported on the rupture of interstitial pregnancy due to its misdiagnosis as normal intrauterine pregnancy. ${ }^{18}$ In a review of 36 cases by Chan et al $41.7 \%$ of interstitial ectopics were misdiagnosed at the first presentation and rupture of interstitial pregnancy occurred in $40 \%$ of these women. ${ }^{19}$ Though a few report a high diagnostic accuracy of about $90 \%$ at an initial ultrasound every missed ectopic should be reviewed in order to minimize and prevent its occurrence. ${ }^{20} 2 \mathrm{D}$ sonography has only a sensitivity of approximately $40 \%$ 
in identifying the exact location of the sac. ${ }^{12} 3 \mathrm{D}$ ultrasound helps to clearly delineate the interstitial portion of fallopian tube facilitating better understanding of anatomical planes.

Interstitial pregnancies can be treated with either conservative or surgical management. Nonsurgical treatment includes systemic/locally injected methotrexate and local injection of other cytotoxic drugs directly into the gestational sac. ${ }^{21}$ As first line of treatment, the Royal College of Obstetricians and Gynaecologists (RCOG) recommends methotrexate in patients with $\beta$-hCG $<5000$ $\mathrm{IU} / \mathrm{mL}$ and ectopic pregnancy smaller than $3.5 \mathrm{~cm}$ to 4 $\mathrm{cm}$ with minimal symptoms. ${ }^{22,23}$ Approximately $10 \%$ to $20 \%$ of patients with interstitial pregnancies who are treated with methotrexate will ultimately require surgery for a rising hCG level, continued pain, or evidence of cornual rupture. ${ }^{24}$ There have been only small case series of interstitial pregnancies treated with locally injected methotrexate or potassium chloride and a universally accepted protocol of either systemic single or multidose regimen or local injection has yet to be identified. ${ }^{25-27}$

Currently, there is no consensus as to whether laparotomy, hysterectomy or cornual resection is better, but however more conservative approaches are preferred like cornuostomy and laparoscopy instead of laparotomy for fertility conservation. ${ }^{28}$ Patients who are submitted to any of these treatments should ideally undergo caesarean section because of the risk of uterine rupture. ${ }^{12,29}$ Though a prevalence of only $0.3 \%$ of recurrent interstitial pregnancy has been reported a follow up in subsequent pregnancy is recommended. ${ }^{30}$ Successful vaginal delivery of healthy babies has been reported after laparoscopic removal of unruptured or ruptured cornual pregnancy. ${ }^{31-33}$ Clear guidelines are yet to be developed regarding future pregnancy management following treatment of these entities as instances of rupture uterus have also been cited in literature. ${ }^{34-36}$

\section{Angular pregnancy}

In 1898 Howard Kelly described angular pregnancy as implantation of the embryo in the lateral angle of the uterine cavity, just medial to the uterotubal junction and to the round ligament. ${ }^{8}$ Specific diagnostic criteria was proposed later which includes clinical presentation with painful asymmetric enlargement of the uterus, directly observed lateral distension of the uterus with or without rupture, accompanied by displacement of the round ligament reflection laterally and retention of the placenta in the uterine angle. ${ }^{37}$ Full-term delivery is likely as the gestational sac descends into the uterine cavity. ${ }^{37,38}$ In cases where the sac might not descend into the uterine cavity there may be tendency for rupture, hence it is also important to look for myometrial discontinuity and hemoperitoneum whenever angular pregnancy is suspected. Angular pregnancies end in abortion in $38.5 \%$ of patients and $23 \%$ of cases are associated with uterine rupture. ${ }^{37,39}$ Cases regarded as angular pregnancies in literature may include interstitial pregnancies, therefore the true incidence of obstetric complications in patients with angular pregnancies remains unclear. Although a strategy of expectant management may be reasonable, continuous and careful monitoring of the mother and fetus is necessary.

Angular pregnancy on ultrasound presents as an eccentrically located gestation sac implanted in the lateral angle of the uterus in the endometrial cavity. Most often there is sufficient myometrium surrounding the sac although focal thinning of myometrium may be seen sometimes. The "surrounding endometrium" sign has been recently proposed as a specific sign for angular pregnancies. ${ }^{40}$ This sign is based on the "double sac sign" (a layer of decidual reaction and a chorionic ring) seen in any intrauterine pregnancy should also be seen in an angular pregnancy but is not seen in interstitial pregnancy.

The same finding has also been reported in MRI where the gestational sac in angular pregnancy is surrounded by T2 hyperintense endometrium, where as in an interstitial pregnancy the sac is surrounded by $\mathrm{T} 2$ hypointense myometrium. ${ }^{41}$ MRI may help to differentiate these conditions, but because of the limited availability and cost factor it cannot be considered as an initial screening tool for assessment.

\section{Cornual pregnancy}

The term cornual ectopic pregnancy should be reserved for pregnancy in women with a uterine anomaly. Cornual pregnancy refers to ectopic pregnancy in a communicating/noncommunicating rudimentary horn of a unicornuate uterus or its intrauterine location in the lateral half of a septate/subseptate/bicornuate uterus. ${ }^{37}$ $\mathrm{Sac}$ is often found laterally in the uterus, which may resemble an interstitial pregnancy but this sac is located medial to the interstitial tube.

In the majority of unicornuate cases, a small noncommunicating rudimentary horn can be seen adjacent to the medial aspect of the unicornuate uterus. ${ }^{42}$ The following criteria to diagnose cornual pregnancy based on ultrasound were proposed by Mavrelos et al. ${ }^{43} \mathrm{~A}$ single interstitial portion of Fallopian tube in the main uterine body, a gestational sac surrounded by myometrium which is mobile and separate from the uterus and a vascular pedicle adjoining the sac to the unicornuate uterus.

The differential diagnosis between cornual and other forms of ectopic pregnancy is important because of the different clinical implications and management strategies. Failure to diagnose a cornual pregnancy in rudimentary horn can lead to serious complications, while an early diagnosis provides the option of safe and effective treatment. $^{44,45}$ Although interstitial pregnancy can be treated by medical or conservative management, such 
management for cornual pregnancy in rudimentary horn is not advisable and should always be managed surgically. ${ }^{43,46}$

To diagnose cornual pregnancy, it is necessary to first identify uterine malformations as mullerian anomalies are associated with poor obstetric outcomes, such as an increased incidence of miscarriage, preterm delivery, an abnormal fetal lie, and cesarean delivery. ${ }^{47}$ However, there are no universally accepted criteria for diagnosing congenital uterine anomalies by using $2 \mathrm{D}$ sonography. ${ }^{48}$ 3D sonography not only depicts uterine malformations but also the exact location of the gestational sac.Though 3D sonography and MRI can be used to clearly evaluate the uterine cavity 3D sonography is preferred for its cost effectiveness and easy availability. ${ }^{49}$

\section{Cornual fibroid}

Cornual fibroids can mimic as ectopic pregnancy and might lead to unnecessary intervention like treatment with methotrexate or laparoscopy or laparotomy. Many instances of surgical intervention has been reported in cases where the fibroid was misinterpreted as an ectopic pregnancy. ${ }^{50}$ Hence understanding that degeneration in fibroids can sometimes cause severe pain and menorrhagea and the need for correlating b-hcg levels with ultrasound findings should always be kept in mind.

\section{CONCLUSION}

Despite technological advances in the ultrasound and the availability and easy access to early pregnancy units, interstitial ectopic pregnancies are often missed. The reasons for misinterpretation are a lack of suspicion, inadequacy of diagnostic expertise and maybe the late presentation of patients.

Even in units where the diagnostic accuracy of cornual/interstitial ectopic pregnancies is high (90\%), these pregnancies can still be missed with routine 2D ultrasound. Early clinical diagnosis aided by threedimensional sonography may contribute towards effective conservative or fertility preserving treatment modalities. Clinicians should therefore to be encouraged to make use of 3D sonography to increase the diagnostic accuracy which would avoid the misdiagnosis of interstitial pregnancy.

\section{Funding: No funding sources \\ Conflict of interest: None declared \\ Ethical approval: Not required}

\section{REFERENCES}

1. Ross R, Lindheim SR, Olive DL, Pritts EA. Cornual gestation: a systematic literature review and two case reports of a novel treatment regimen. J Min Inv Gynecol. 2006;13:74-8.
2. Tulandi T, Al-Jaroudi D. Interstitial pregnancy: results generated from the Society of Reproductive Surgeons registry. Obstet Gynecol. 2004;103:47-50.

3. Stovall TG, McCord ML. Early pregnancy loss and ectopic pregnancy. In: Berek JS, Adashi EY, Hillard PA, editors. Novak's Gynecology. $12^{\text {th }}$ ed. Baltimore: Williams and Wilkins; 1996:487-524.

4. Tulandi T, Saleh A. Surgical management of ectopic pregnancy. Clin Obstet Gynecol. 1999;42(1):31-8.

5. Faraj R, Steel M. Review Management of cornual (interstitial) pregnancy. TOG. 2007;9(4):249-55.

6. Patil M. Ectopic pregnancy after infertility treatment. J Hum Reprod Sci. 2012;5(2):154-65.

7. Nardo LG. The dilemma of recurrent ectopic pregnancy after tubal surgery and in-vitro fertilization. What to do? Reprod Biomed Online. 2005; 10:300.

8. Tanaka Y, Mimura K, Kanagawa T, Kajimoto E, Takahashi K, Kakigano A, et al. Three-dimensional sonography in the differential diagnosis of interstitial, angular, and intrauterine pregnancies in a septate uterus. J Ultrasound Med. 2014;33:2031-5.

9. Tanaka Y, Mimura K, Kanagawa T. Interstitial pregnancy resulting in a viable infant coexistent with massive perivillous fibrin deposition: a case report and literature review. AJP Rep. 2014;4:29-32.

10. Kalidindi M, Shahid A, Odejinmi F. Expect the unexpected: The dilemmas in the diagnosis and management of interstitial ectopic pregnancy: case report and literature review. Gynecol Minimal Inv Ther. 2016;5(1):35-7.

11. Timor-Tritsch IE, Monteagudo A, Matera C, Veit CR. Sonographic evolution of cornual pregnancies treated without surgery. Obstet Gynecol. 1992;79:1044-9.

12. Ackerman TE, Levi CS, Dashefsky SM, Holt SC, Lindsay DJ. Interstitial line: sonographic finding in interstitial (corneal ectopic pregnancy. Radiol. 1993;189:83-7.

13. Hafner T, Aslam N, Ross JA, Zosmer N, Jurkovic D. The effectiveness of non-surgical management of early interstitial pregnancy: a report of ten cases and review of the literature. Ultrasound Obstet Gynecol. 1999;13:131-6.

14. Jurkovic D, Mavrelos D. Catch me if you scan: ultrasound diagnosis of ectopic pregnancy. Ultrasound Obstet Gynecol. 2007;30(1):1-7.

15. Hamouda ESM, Littooij AS, Thia EW, Ong CL. Ruptured interstitial ectopic pregnancy at 18 weeks gestation diagnosed by MRI: a case report. JRCR. 2013;7(10):34-42.

16. Kun WM, Tung WK. On the look out for a rarityinterstitial/cornual pregnancy. Eur J Emerg Med. 2001;8:147-50.

17. DeWitt C, Abbott J. Interstitial pregnancy: a potential for Misdiagnosis of ectopic pregnancy with emergency department ultrasonography. Ann Emerg Med. 2002;40:106-9.

18. Petersen KR, Larsen GK, Nørring K, Jensen FR. Misdiagnosis of interstitial pregnancy followed by 
uterine cornual rupture during induced midtrimester abortion. Acta Obstet Gynaecol Scand. 1992;71:316e318.

19. Chan LYS, Fok WY, Yuen PM. Pitfalls in diagnosis of interstitial pregnancy. Acta Obstet Gynaecol Scand. 2003;82:867e870.

20. MacRae R, Olowu O, Rizzuto MI, Odejinmi F. Diagnosis and laparoscopic management of 11 consecutive cases of cornual ectopic pregnancy. Arch Gynaecol Obstet. 2009;280:59e64.

21. Moawad NS, Mahajan ST, Moniz MH, Taylor SE, Hurd WW. Currentdiagnosis and treatment of interstitial pregnancy. Am J Obstet Gynecol. 2010;202:15-29.

22. Sharma N, Upasana R. An ectopic pregnancy in the tubalinterstitium: Beware! J Clin Diagn Res. 2013;7:160-2.

23. Cucinella G, Calagna G, Rotolo S, Granese R, Saitta S. A interstitial pregnancy: a 'road map' of surgical treatment basedon a systematic review of the literature. Gynecol Obstet Invest. 2014;78:141-9.

24. Practice Committee of American Society for Reproductive Medicine. Medical treatment of ectopic pregnancy: a committee opinion. Fertil Steril. 2013;100:638-44.

25. Jermy K, Thomas J, Doo A, Bourne T. The conservative management of interstitial pregnancy. BJOG. 2004;111:1283-8.

26. Lau S, Tulandi T. Conservative medical and surgical management of interstitial ectopic pregnancy. Fertil Steril. 1999;72:207-15.

27. Soriano D, Vicus D, Mashiach R, Schiff E, Seidman $\mathrm{D}$, Goldenberg M. Laparoscopic treatment of cornual pregnancy: a series of 20 consecutive cases. Fertil Steril. 2008;90:839-43.

28. Singh N, Tripathi R, Mala YM, Batra A. Diagnostic dilemma incornual pregnancy-3D ultrasonography may Aid!! J Clin Diagn Res. 2015;9:12-3.

29. Wang J, Huang D, Lin X, Saravelos SH, Chen J. Incidence of interstitial pregnancy after in vitro fertilization/embryo transfer and the outcome of a consecutive series of 38 cases managed by laparoscopic cornuostomy or cornual repair. J Minim Invasive Gynecol. 2016;9:134-5.

30. Siow A, Ng S. Laparoscopic management of 4 cases of recurrent cornual ectopic pregnancy and review of literature. J Minim Invasive Gynecol. 2011;18:296-302.

31. Surbone A, Cottier O, Vial Y, Francini K, Hohlfeld $P$. Interstitial pregnancies' diagnosis and management: an eleven cases series. Swiss Med Wkly. 2013;143:13736.

32. Sills ES, Perloe M, Kaplan CR, Sweitzer CL, Morton PC, Tucker MJ. Uncomplicated pregnancy and normal singleton delivery after surgical excision of heterotopic (cornual) pregnancy following in vitro fertilization/embryo transfer. Arch Gynecol Obstet. 2002;266:181-4.

33. Ben-Ami I, Panski M, Ushakov F, Vaknin Z, Herman A, Raziel A. Recurrent heterotopic pregnancy after bilateral salpingectomy in an IVF patient: case report. J Assist Reprod Genet. 2006;23:333-5.

34. Auamkul S. Rupture of gravid uterus after cornual resection. A case report. J Reprod Med. 1970;5(5):218-20.

35. Tulandi T, Vilos G, Gomel V. Laparoscopic treatment of interstitial pregnancy. Obstet Gynecol. 1995;85(3):465-7.

36. Su CF, Tsai HJ, Chen GD, Shih YT, Lee MS. Uterine rupture at scar of prior laparoscopic cornuostomy after vaginal delivery of a full-term healthy infant. J Obstet Gynaecol Res. 2008;34(4 Pt 2):688-91.

37. Jansen RP, Elliott PM. Angular intrauterine pregnancy. Obstet Gynecol. 1981;58:167-75.

38. Alves JA, Alves NG, AlencarJúnior CA, Feitosa FE, da Silva Costa F. Term angular pregnancy: successful expectant management. J Obstet Gynaecol Res. 2011;37:641-4.

39. Chang $\mathrm{FW}, \mathrm{Yu} \mathrm{MH}$, Chen WH. An angular pregnancy of a bicornuate uterus. Int $\mathbf{J}$ Gynaecol Obstet. 2003;81:219-20.

40. Grant A, Murji A, Atri M, Epid D. Can the presence of a surrounding endometrium differentiate eccentrically located intrauterine pregnancy from interstitial ectopic pregnancy? J Obstet Gynaecol Can. 2017;39(8):627-34.

41. Parker RA, Yano M, Tai AW, Friedman M, Narra $\mathrm{VR}$, Menias CO, et al. MR imaging findings of ectopic pregnancy: a pictorial review. Radiograph. 2012;32(5):1445-60.

42. Jayasinghe Y, Rane A, Stalewski H, Grover S. The presentation and early diagnosis of the rudimentary uterine horn. Obstet Gynecol. 2005;105:1456-67.

43. Mavrelos D, Sawyer E, Helmy S, Holland T, BenNagi J, Jurkovic D. Ultrasound diagnosis of ectopic pregnancy in thenon-communicating horn of a unicornuate uterus (cornual pregnancy). Ultrasound Obstet Gynecol. 2007.

44. DeNicola RR, Peterson MR. Pregnancy in rudimentary horn of uterus. Am J Surg. 1947;73:382-6.

45. Nahum GG. Rudimentary uterine horn pregnancy. The $20^{\text {th }}$ century worldwide experience of 588 cases. J Reprod Med. 2002;47:151-63.

46. Martin JN, McCaulJFt. Emergent management of abdominal pregnancy. Clin Obstet Gynecol. 1990;33:438-47.

47. Cunningham FG, Leveno KJ, Bloom SL, Hauth JC, Rouse DJ, Spong CY. Reproductive tract abnormalities. In: Cunningham FG, Leveno KJ, Bloom SL, Hauth JC, Rouse DJ, Spong CY (eds.) Williams Obstetrics. 23 ${ }^{\text {rd }}$ ed. New York, NY: McGraw-Hill; 2010:890-911.

48. Saravelos SH, Cocksedge KA, Li TC. Prevalence and diagnosis of congenital uterine anomalies in women with reproductive failure: a critical appraisal. Hum Reprod Update. 2008;14:415-29.

49. Bermejo C, Martínez Ten P, Cantarero R. Threedimensional ultrasoundin the diagnosis of müllerian duct anomalies and concordance withmagnetic 
resonance imaging. Ultrasound Obstet Gynecol. 2010;35:593-601.

50. Ogu RN, Enyindah C, Orazulike N, Okpani AO. Submucous uterine fibroid mimicking ruptured ectopic gestation: a case report. J Clin Diagn Res. 2014;8(7):OD08-9.
Cite this article as: Selvaraj LR, Ziyaulla T, Umapathy S. Diagnostic dilemmas of an eccentrically located gestation sac: role of 3D ultrasound. Int J Reprod Contracept Obstet Gynecol 2020;9:156-64. 